David Leedham
is a consulting
director for
Ember Services,
a consultancy
specializing in
commercial insight
for strategic and
operational customer
management
developments.
He has advised
on contact centre
and customer
management
developments for
over 15 years. Ember
was an advisor to
Ofcom for their
recent review into
dealing with the
issues of silent and
abandoned calls
(www.emberservices.
com).

David Leedham

is a consulting

director for

Ember Services,

a consultancy

specializing in commercial insigh

for strategic and operational customer

management

developments.

He has advised

on contact centre

and customer

management

developments for

over 15 years. Ember

was an advisor to

Ofcom for their

recent review into

dealing with the

issues of silent and

abandoned calls

com).

New regulation

\section{Tackling silent and abandoned calls - Are you compliant with the revised UK policy?}

\section{David Leedham}

Journal of Direct, Data and Digital Marketing Practice (2011) 12, 277-280. doi:10.1057/dddmp.2010.40

\section{Summary}

This paper provides a brief history of the Ofcom actions to address the issue of silent and abandoned calls and the resulting harm these cause. It outlines the most recent Policy changes and discusses the implications of these to those using outbound dialling technology.

Released on 1 October 2010 was the long-awaited Ofcom revised Statement on Tackling Silent and Abandoned Calls.

Central to Ofcom's powers under the Communications Act 2003, is the ability to issue and enforce notifications where it has reasonable grounds for believing that a person has persistently misused an electronic communications network or electronic communications services.

Ofcom published a Statement of Policy on 1 March 2006. It subsequently published a Revised Statement of Policy on 10 September 2008 and made an amendment to this on 30 October 2009 where it identified making abandoned or silent calls as examples of persistent misuse. After the period of consultation in 2010, Ofcom have now revised their Policy and are expecting firms to comply within 4 months.

At the same time parliament has confirmed the increase in maximum fine for persistent misuse from $£ 50,000$ to $£ 2,000,000$ and the NAO report into Ofcom published on 10 November 2010 claimed that there remained 'persistent issues' regarding the regulation of silent calls. The stakes have risen sharply.

\section{Changes to the guidelines}

The new Guidelines amend regulations under two broad themes: introduction of new policy and the clarification of the existing policy.

(a) New policy is limited to one amendment as follows:

\footnotetext{
'A1.55 When a call has been identified by AMD [Answering Machine Detection] equipment as being picked up by an answer machine (including AMD false positives), any repeat calls to that specific number within the same 24 hour period may only be made with the guaranteed presence of a live operator.'
} 


\section{Clarification of existing policy}

\section{Targeting of repeat silent calls}

(b) The Clarification of existing policy falls into five broad areas:

(1) the method for calculating abandoned call rates (para A1.30-A1.50);

(2) the methods for calculating and testing for False Positive Rates where Answer Machine Detection is used (para A1.37);

(3) confirming when messages must start to be played on abandoned calls (para A1.51);

(4) information messages left on abandoned calls (para A1.52); and

(5) the definition of Campaign within the regulations (para A1.21).

\section{The eight key points of policy}

The key elements of the regulatory regime can now be summarized as follows:

\begin{tabular}{|c|c|}
\hline Short name & Policy requirement \\
\hline $3 \%$ policy & $\begin{array}{l}\text { 1. Less than } 3 \% \text { abandonment per campaign (with correct } \\
\text { calculation and estimate for AMD FP if used) over a } 24 \text { hour } \\
\text { period. }\end{array}$ \\
\hline Two second Policy & $\begin{array}{l}\text { 2. For each abandoned call a recorded message is played } \\
\text { within } 2 \text { seconds of pickup or start of salutation containing } \\
\text { the appropriate information only. }\end{array}$ \\
\hline 15 second rule & $\begin{array}{l}\text { 3. That for those calls not answered it was rung for a min of } \\
15 \text { seconds before termination. }\end{array}$ \\
\hline 72 hour policy & $\begin{array}{l}\text { 4. When an abandoned call is made, any repeat call within } \\
72 \text { hours is made with a live operator. }\end{array}$ \\
\hline CLI presented & $\begin{array}{l}\text { 5. All outbound calls carry a geographic or non geographic CLI } \\
\text { to allow a return call. }\end{array}$ \\
\hline No marketing & $\begin{array}{l}\text { 6. Any consumer call made in response to } 5 \text {, is not used to } \\
\text { market to them without the callers consent. }\end{array}$ \\
\hline Record keeping & $\begin{array}{l}\text { 7. Records are kept for } 6 \text { months to demonstrate compliance to } \\
\text { the above. }\end{array}$ \\
\hline AM 24 hour policy & $\begin{array}{l}\text { 8. Where AMD technology indicates an answerphone is } \\
\text { reached, any repeat call within } 24 \text { hours is made with a live } \\
\text { operator. }\end{array}$ \\
\hline
\end{tabular}

\section{Purpose of the changes}

In themselves the new changes may appear relatively innocuous, but we believe that the new guidelines not only significantly reinforce the regulatory environment, particularly for AMD users, but also show a renewed intent by Ofcom to tackle the issue. On the back of the new regulations we expect to see a significant increase in enforcement action.

Ofcom appear to be reacting to increased public and political pressure on the issue of silent calls, and they are at pains to lay out their evidence in the new Statement. Their target here is Answer Machine Detection technology that they identify as being responsible for the majority of repeat silent calls as some calls will be wrongly identified as answer machines and the real consumer at the end of the line will be 'hung up' on with no message played. ${ }^{1}$ 


\section{Answer machine detection technology and false positives}

\section{Is the use of AMP now prohibited?}

The new policy initiative directly addresses AMD users and attempts to limit repeat silent calls by imposing a blanket 24 hour ban on repeat calling ALL numbers that have been identified by technology as Answer Machine answered, unless the presence of an agent can be guaranteed, that is in effect, requiring that all predictive dialling is turned off. This will ensure that those consumers wrongly identified as answer machines will not be hassled again within the 24 hour period; it also causes a reduction in efficiency of contact rates, as true answer machines cannot be redialled for the 24 hour period. This removes the possibility of the consumer being contacted if and when they return home (if within that 24 hour period).

In addition, most of the tidying up of previous guidelines centres around clarifying the AMD False Positive issue - how they should be included in calculations and how they should be tested for, including advocacy of external auditors.

The new regulations do not ban the use of AMD technology; this is a proposal that Ofcom analyse in the regulations and then reject on the basis of its economic benefit to operators and, through them, indirectly to consumers. However, they do make its use that much more difficult and its testing that much more proscribed that their effect may in reality be something similar.

\section{The effect on AMD users}

We believe that these changes will have a material impact on operations that are using AMD - we estimate this to be approximately 50 per cent of outbound marketing operations and significantly more in the debt collection industry. This will be felt in the following ways:

- Data - we suspect that campaigns will be shortened. As a campaign runs, Answer Machine call ratios inevitably rise (the people who are generally at home have already been contacted and thus are removed from calling lists). The new proposals will make the end of campaign activity less economic and so campaigns will be shortened. This may in turn result in pressure for more data per se or more detailed and segmented data to feed decisions on when to call.

- Profitability - it may become uneconomic to run some campaigns at all and these will be pulled. In reality, we expect this to be limited and workarounds will be found.

On the plus side, it is clear that the proposals will have a material beneficial impact on the consumer as silent calls and particularly repeat silent calls will be reduced — thus meeting Ofcom's primary duty of protecting the public from persistent misuse. 


\section{Required testing and review}

\section{Timings and independent audit}

\section{Essential actions}

So what should outbound operators consider as a result of the new Statement? There are four headline recommendations:

1. Abandon rate calculation - Review your calculations for your abandon rate. This applies to all operators not just AMD users. The Statement clarifies the calculation and it may well be that you can build more tolerances into your over-dialling than you currently believe. The calculations are complex but the benefit could be significant. It is worth getting advice.

2. Messages - Ensure your messages on abandoned calls are compliant.

3. False Positive compliance (AMD users only) - It is clear that Ofcom have AMD in their sights. If you are using it, make sure you understand it, that you are using it compliantly and that this has been duly evidenced. Ofcom have been clearer on testing methodologies and have advocated the use of external auditors. Make sure you have the evidence that you are compliant and keep that evidence up to date. If you do not have the evidence of compliance - turn AMD off. A $£ 2 \mathrm{~m}$ fine is your risk.

4. New 24 hour rule (AMD users only) - Ensure that your calling procedures and dialler settings allow for compliance with the new rule. Assess the impact that this will have on your productivity and the level of list penetration that is now economic.

\section{Timing and next steps}

All the above needs to be completed within 4 months from the Policy publication date, which means 1 February 2010.

Ember Services have put together a suite of services to help operators work in the new environment. Supported or endorsed by various industry bodies, and with Ofcom advocating the use of external auditors, now is a good time to review your compliance position as well as take stock of best practice learning and leadership for your outbound activities.

\section{David Leedham, Ember Services}

David.Leedham@emberservices.com

Note

1 Note that calls abandoned in the normal course of predictive dialling have already been legislated for and should be limited to 3 per cent and have a message played on them - hence they are not 'silent'. AMD False positives are potentially unlimited and will be silent as the operation is not even aware they are being made. 